\section{Long distance telemetry of fetal heart rate from patients' homes using public telephone network}

Sporadic reports have been published on intrapartum fetal heart rate telemetry over short distances, but there have been conflicting reports on its acceptability to patients and its influence on the course of labour. ${ }^{12}$ Transmission of electrocardiographic signals in adults using the public telephone network has also been reported. ${ }^{3}$ We describe a new technique of monitoring the fetal heart rate antenatally by telemetry. This technique may be used from the patient's home through the public telephone network, for prolonged periods of time and over distances of many miles. The heart signal may then be computer processed and displayed in real time within the obstetric unit for immediate assessment.

\section{Patients, methods, and results}

Thirty telecardiograms were recorded in 11 women, from 16 weeks' gestation to term. Twenty recordings were transmitted from five patients' homes and 10 within the hospital, all using the telephone network.

In the patient's home a Sonicaid D205 (2 MHz) portable ultrasonic fetal heart rate detector was used, and its transducer was held against the abdominal wall in an appropriate position. By placing the handset of the telephone so that its mouthpiece was close to the detector's loudspeaker the heart signal was fed into the public telephone network. Recording time was usually 30 minutes. In the obstetric unit, the incoming signal was passed into a preprocessor and then into a Hewlett Packard 9826 (or HP 9825) desktop computer running the HPL program Teleplot, written by KJD. An error detection algorithm ${ }^{4}$ identified signal noise and validated genuine heart periods. Mean heart rates were calculated every 3.75 seconds $(1 / 16 \mathrm{~min})^{5}$ and displayed on the visual display unit as a continuous heart rate versus time trace, almost indistinguishable from a standard paper trace (figure).

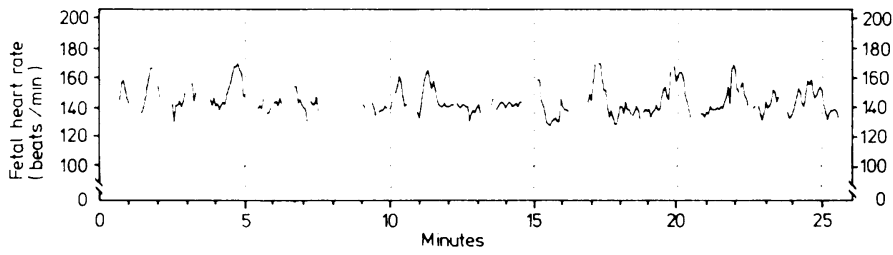

Telecardiogram recorded at 37 weeks' gestation in patient's own home and without supervision. Gaps in recording denote signal loss. The baseline fetal heart rate was 140 beats/min and multiple accelerations were seen. No decelerations were seen.

The electronic and computing methods are to be described elsewhere. Signal losses were computed. In supervised recordings no difference was found between those made at home and those made in hospital. Unsupervised recordings, however, showed a $53 \%$ greater signal loss. Of the 30 telecardiograms, 28 were clearly interpretable: no abnormalities were seen.

\section{CASE REPORT}

A 31 year old woman with insulin dependant diabetes, underwent inpatient cardiotocography daily from 35 weeks in her first pregnancy. Decelerations of the fetal heart occurred at 37 weeks and she was delivered by emergency caesarean section.

We managed her second pregnancy on an outpatient basis, but weekly attendance at hospital was difficult for her because she lived 14 miles $(23 \mathrm{~km})$ away and had no transport. At 35 weeks she started her own daily, unsupervised fetal heart recordings at home, transmitting them to us by telephone for real time processing by the computer in the obstetric department. The figure shows one of her recordings. No signs of fetal compromise were observed over 10 days' telemetric monitoring and we would have been happy to continue monitoring in this manner. Unfortunately, polyhydramnios then developed and she was admitted to hospital for the remainder of her pregnancy.

Even allowing for telephone charges and a share in the cost of staff and equipment, the cost of monitoring her from her home each day was less than $6 \%$ of the daily cost of a hospital bed.

\section{Comment}

Our results show that, in selected patients, antenatal monitoring of the fetal heart rate may be carried out safely and satisfactorily while the patient remains at home, and at a fraction of the cost of hospital admission.

Naturally, any abnormality found in the fetal heart rate-for example, decelerations-will warrant admission to hospital. Nevertheless, as most telecardiograms recorded at home will be entirely normal, only those few patients from whom sinister recordings are obtained would need admission for more intensive assessment.

AJD and NAJG were supported by the Welsh Office. We thank Hewlett Packard, and particularly Djohan Muliawan for loan of the HP 9825; and Action Research for the Crippled Child and the British Heart Foundation for funding the HP 9826 .

' Flynn AM, Kelly J, Hollins G, Lynch PF. Ambulation in labour. Br Med $\mathcal{f}$ 1978;ii:591-3.

${ }^{2}$ Calvert JP, Newcombe RG, Hibbard BM. An assessment of radiotelemetry in the monitoring of labour. Br $\mathcal{F}$ Obstet Gynaecol 1982;89: 285-91.

${ }^{3}$ Cooper JK, Caceres CA. Telemetry by telephone. In: Caceres CA, ed. Biomedical telemetry. New York: Academic Press, 1965:15-37.

${ }^{4}$ Dalton KJ. Real time computer calculation of heart rate and its variability in the human fetus using an "indirect" or transabdominal ECG signal. In: Paul JP, Jordan MM, Ferguson-Pell MW, Andrews BJ, eds. Computing in medicine. London: Macmillan, 1981:301-8.

Dawes GS, Visser GHA, Goodman JDS, Redman CWG. Numerical analysis of the human fetal heart rate: the quality of ultrasound records. Am $\mathcal{F}$ Obstet Gynecol 1981;141:43-52.

(Accepted 28 February 1983)

Fetal Physiology Unit, Department of Obstetrics and Gynaecology, Welsh National School of Medicine, Cardiff CF4 4XN

KEVIN J DALTON, DPHIL, MRCOG, lecturer and senior registrar ANDREW J DAWSON, MB, MRCOG, research registrar NIGEL A J GOUGH, electronics technician

\section{Accuracy of indirect blood pressure measurement in the elderly}

A report of large discrepancies between direct and indirect measurements of blood pressure with increasing age ${ }^{1}$ led to use of the term pseudohypertension in the elderly and speculation that indirect measurement is inaccurate in the elderly. ${ }^{2}$ We assessed the effect of age on the accuracy of indirect measurements of blood pressure by comparing simultaneous direct and indirect measurements in elderly and young patients with high blood pressure. The ethical justification for performing direct intra-arterial measurement of blood pressure in the elderly patients was based on the fact that if the results of Spence $e t a l^{1}$ were valid direct measurement was indicated to determine the true blood pressure; if we established that pseudohypertension was not a true clinical entity, however, unnecessary direct measurement in the elderly would be avoided in future.

\section{Patients, methods, and results}

Forty elderly patients aged $60-80$ (mean 68 ) and 20 young patients aged $24-43$ (mean 38) were entered into the study consecutively from the clinic. All gave informed consent. The protocol was approved by the hospital ethics committee.

With the patient supine, indirect systolic and diastolic (phase V) blood pressures were recorded simultaneously in both arms with a standard mercury sphygmomanometer and cuffs with bladder dimensions of $22.5 \times$ $12.5 \mathrm{~cm}$. The cuffs were interconnected so that cuff pressures were identical in both arms. There was no significant difference in left arm circumferences between the groups. Direct blood pressure was measured with a 20 gauge Teflon cannula inserted into the radial artery and attached by a saline filled manometer line to a pressure transducer connected to an amplifier oscilloscope 
and strip recorder. Great care was taken with calibration, and the frequency response of the entire system was flat to $15 \mathrm{~Hz}$. Direct intra-arterial recording were compared with simultaneous indirect recordings made on the opposite arm, an event marker indicating on the strip recorder the first and last Korotkoff sounds. Indirect recordings were corrected for the difference between arms. Student's $t$ test was used for comparison within groups (paired) and between groups (unpaired). The relation between direct and indirect pressures was compared between the two groups by covariance analysis.

The figure shows the relation between direct and indirect pressures in both age groups. Indirect pressure underestimated direct systolic pressure by $4 \cdot 4 \pm$ $1.3 \mathrm{~mm} \mathrm{Hg}$ in the elderly $(\mathrm{p}<0.005)$ and $7.0 \pm 1.6 \mathrm{~mm} \mathrm{Hg}$ in the young $(\mathrm{p}<0.001)$ and overestimated direct diastolic pressure by $9.2 \pm 1.0 \mathrm{~mm} \mathrm{Hg}$ $(\mathrm{p}<0.001)$ and $10.4+1.1 \mathrm{~mm} \mathrm{Hg}(\mathrm{p}<0.001)$ respectively. These differences between techniques were not significantly different in the two age groups.

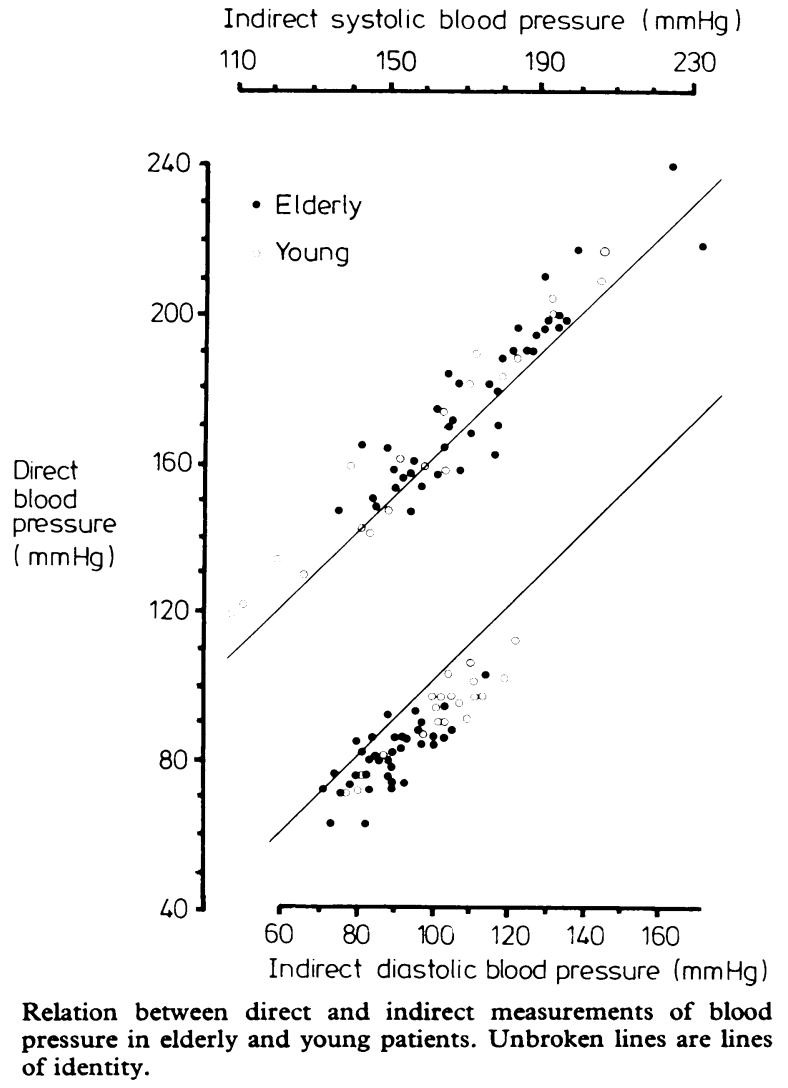

The correlation between direct and indirect systolic blood pressure was significant in both groups (elderly: $r=0.92, p<0.001$; young: $r=0.97$, $\mathrm{p}<0.001)$. There was a similar positive correlation for diastolic pressure (elderly: $r=0.76, p<0.001$; young: $r=0.93, p<0.001$ ). Covariance analysis showed no difference between age groups in the agreement between direct and indirect pressures or in the slopes of the regression lines, which did not differ from unity.

\section{Comment}

The criteria for therapeutic intervention are ill defined in elderly patients with hypertension. ${ }^{3}$ The report $^{1}$ of inaccuracies in the standard method of measuring blood pressure in the elderly added to this problem. There were, however, potential sources of error in this study: the patients were suspected of having large differences between direct and indirect pressures, the frequency response characteristics of the recording system were not stated, blood pressure recordings were not simultaneous, and, finally, the dimensions of the inflatable bladder used to measure indirect pressure $(10 \times 14 \mathrm{~cm})$ might give a falsely high pressure. ${ }^{4}$ Indeed, when a larger cuff was used the differences between direct and indirect measurements in the elderly were greatly reduced. These sources of error were excluded from our study, and we could not find any significant difference in the relations between indirect and direct pressures in the young and old. There were, how ever, discrepancies between direct and indirect measurements in both age groups, which cannot be explained by the level of blood pressure or arm circumference. Three of the young patients and seven of the elderly patients had differences in systolic pressure of $14 \mathrm{~mm} \mathrm{Hg}$ or more, and similar differences were observed for diastolic pressures in five of the young and 11 of the elderly patients.

This study shows that the standard technique of measuring blood pressure with a mercury sphygmomanometer is as accurate in the elderly as it is in young patients, and the indications for direct intraarterial measurement are no different in the elderly than in other age groups.

We are grateful for support from the Irish Heart Foundation, the Medical Research Council of Ireland, Ciba Laboratories, and the Royal College of Surgeons in Ireland and for the expert help and advice of Dr John Blackburn, Westminster Hospital, London.

${ }^{1}$ Spence JD, Sibbald WJ, Cape RD. Pseudohypertension in the elderly. Clin Sci Mol Med 1978;55, suppl 4:399-402.

${ }^{2}$ Anonymous. Hypertension in the over-60s. [Editorial]. Lancet 1980; 1396.

${ }^{3}$ O'Malley K, O'Brien E. Management of hypertension in the elderly. N Engl f Med 1980;302:1397-401.

- King GE. Taking the blood pressure. $\mathcal{F} A M A$ 1969;209:1902-4.

(Accepted 22 February 1983)

Blood Pressure Clinic, Charitable Infirmary, Dublin 1, and Department of Clinical Pharmacology, Royal College of Surgeons in Ireland, Dublin 2

WILLIAM G O'CALLAGHAN, MRCPI, research fellow DESMOND J FITZGERALD, MRCPI, research fellow KEVIN O'MALLEY, MD, professor of clinical pharmacology EOIN O'BRIEN, FRCPI, consultant physician (cardiology)

Correspondence to: Dr E O'Brien, Blood Pressure Clinic, Charitable Infirmary, Jervis Street, Dublin 1.

\section{Influence of ranitidine on plasma metoprolol and atenolol concentrations}

A previous report indicated that ranitidine failed to alter the pharmacokinetics of propranolol, ${ }^{1}$ although cimetidine exerts a considerable influence. ${ }^{2}$ Although both of these $\mathrm{H}_{2}$-receptor antagonists reduce liver blood flow, ranitidine differs from cimetidine in not appearing to affect the hepatic metabolism of certain drugs. We studied the effect of ranitidine on metoprolol, another $\beta$-receptor antagonist that is predominantly metabolised in the liver and whose metabolism is also altered by coadministration of cimetidine. ${ }^{2}$ We used the predominantly renally excreted $\beta$-receptor antagonist atenolol as a control.

\section{Methods and results}

The pharmacokinetics of metoprolol and atenolol were studied in six healthy volunteers after seven days of oral treatment with each drug alone (metoprolol $100 \mathrm{mg}$ twice daily, atenolol $100 \mathrm{mg}$ daily). The pharmacokinetic profile of the drugs was then re-examined after a further seven days of combined oral treatment with ranitidine $(150 \mathrm{mg}$ twice daily)-that is, intra-subject comparison was performed. Blood was collected throughout the study (before the morning dose and three hours later) and at appropriate intervals up to 24 hours after the last morning dose on the seventh day (during wash out). Plasma concentrations of atenolol and metoprolol were determined by measuring the fluorescence on thin layer chromatography plates. ${ }^{3} 4$

The table shows the results of the pharmacokinetic analysis. Carry over effects between the four treatments were excluded. The kinetics of atenolol were not significantly altered by concurrent administration of ranitidine, whereas the area under the plasma concentration time curve for metoprolol from 0 to 24 hours on day 7 increased by about $50 \%(p<0.05)$ with ranitidine

Mean $上 S E M$ kinetic variables on day $7(n=6)$

\begin{tabular}{|c|c|c|c|}
\hline Treatment & $\begin{array}{l}\text { Peak concentration } \\
(\mathrm{ng} / \mathrm{ml})\end{array}$ & $\begin{array}{l}\text { Area under curve } \\
(\mathrm{ng} / \mathrm{ml} \mathrm{h})\end{array}$ & $\underset{\text { (h) }}{\text { Half life }}$ \\
\hline $\begin{array}{l}\text { Metoprolol alone } \\
\text { Metoprolol + ranitidine } \\
\text { Atenolol alone } \\
\text { Atenolol + ranitidine }\end{array}$ & $\begin{array}{l}198 \cdot 8 \pm 23 \cdot 3 \\
266 \cdot 0 \pm 40 \cdot 4 \\
660 \cdot 1+117 \cdot 1 \\
621 \cdot 3+103 \cdot 8\end{array}$ & $\begin{array}{l}1333 \cdot 8+115 \cdot 6 \\
2069 \cdot 9+435 \cdot 4 \\
5786 \cdot 8+979 \cdot 9 \\
6635 \cdot 3+931 \cdot 1\end{array}$ & $\begin{array}{l}3.9+0.2 \\
6.0+0.4 \\
7.0+0.7 \\
8.5+0.9\end{array}$ \\
\hline
\end{tabular}

(1)

,

